\title{
Charge properties of mixtures of minerals with variable and constant surface charge
}

\author{
L. MADRID, E. DÍAZ \& F. CABRERA
}

Centro de Edafología y Biología Aplicada del Cuarto, Apartado 1052, Sevilla, Spain

\section{SUMMARY}

Surface charge of mixtures of lepidocrocite and illite determined by adsorption of potential-determining and electrolyte ions is studied as a function of $\mathrm{pH}$ and $\mathrm{NaCl}$ concentration. Deviations between results obtained by both methods were a function of the illite content of the mixtures, and can be mainly attributed to coatings of hydroxyaluminium complexes on the constant charge surfaces of the clay mineral, which can react with $\mathrm{H}^{+}$ions or release exchange sites by precipitation of well-formed hydroxides. These coatings of aluminium complexes can cause $\mathrm{H}^{+}$ consumptions similar to those due to lepidocrocite.

Some ideas are put forward for modelling charge properties of mixed systems.

\section{INTRODUCTION}

According to their behaviour in the solid/solution interphase, ions in solution can be classified into three groups. (a) Ions which show high affinity for the surface, being indistinguishable from those present in the solid. When these ions are adsorbed they become part of the surface, providing it with a net charge. For scarcely soluble oxides and hydroxides, $\mathrm{H}^{+}$and $\mathrm{OH}^{-}$belong to this group, and the surface electric potential ('outer' or 'Volta' potential) is determined by their solution concentrations: they are potential-determining ions, p.d.i. (b) A second group of ions with high affinity for the surface, and like the p.d.i. they are adsorbed on layers close to the surface influencing its electric charge and potential. They are specifically adsorbed ions, s.a.i., and a feature which distinguishes them from the p.d.i. is that prior to adsorption the former are not an integral part of the solid phase or the solvent. (c) Ions with low (or negligible) affinity for the surface, which do not approach the surface nearer than the outer Helmholtz plane or the diffuse layer. They are attracted to the surface by electrostatic forces, compensating its net charge; these are indifferent ions, i.i. In some models for ion adsorption, the affinity of each ion for the surface is represented by a binding constant. It has been shown (Bowden et al., 1977; Barrow'et al., 1980; Madrid et al., 1983) that results are best accounted for if ions such as $\mathrm{Na}^{+}$and $\mathrm{Cl}^{-}$are supposed to be not fully indifferent, so that they have small but non-zero binding constants, about eight orders of magnitude lower than those for $\mathrm{H}^{+}$or $\mathrm{OH}^{-}$ions.

It is a well-known fact that an important proportion of the surface electric charge of many minerals does not depend on the solution composition, but is caused by isomorphic substitutions within their crystal structures, so that it has a definite constant value. This charge is known as 'structural', 'constant' or 'permanent' charge, to distinguish it from that due to ion adsorption, which is known as 'variable' or 'pH-dependent' charge.

In a previous paper (Madrid et al., 1983), the surface charge of a series of synthetic and natural materials was measured by adsorption of potential-determining and indifferent ions. Those materials which were believed to have charge only due to adsorption of p.d.i. gave similar results by both methods. In contrast, materials which were known to contain constant charge minerals showed important differences between the charge measured by adsorption of p.d.i. and of i.i., and such differences could be explained by the presence of permanent charge. 
As a consequence of the conclusions of Madrid et al. (1983) and following the idea suggested by Parker et al. (1979), the present paper shows measurements by both methods of the surface charge of mixtures of a synthetic iron oxide and an illite from Montana. The charge of the former is expected to be essentially $\mathrm{pH}$-dependent, and that of the latter should be predominantly of structural origin.

\section{MATERIALS AND METHODS}

The iron oxide was a sample of lepidocrocite (LP) similar to that described in a previous paper (Madrid et al., 1983), and the illite (IL) was a sample from Silver Hill, Montana, provided by the Clay Minerals Society's Source Clays Repository (sample IMt-1). The illite was ground to pass through a $0.08 \mathrm{~mm}$ sieve. No grinding was necessary for the iron oxide, as its particle size was smaller than $0.08 \mathrm{~mm}$. The BET specific surface area of LP was $116 \mathrm{~m}^{2} \mathrm{~g}^{-1}$, and that of IL ('external' surface) was $29 \mathrm{~m}^{2} \mathrm{~g}^{-1}$. These values are given only for illustrative purposes, as it is known that surface areas accessible to ion adsorption can be much larger than those measured by $\mathrm{N}_{2}$ adsorption particularly in the case of layer silicates. The CEC of IL determined by neutral $1 \mathrm{M} \mathrm{NH}_{4} \mathrm{OAc}$ was $0.22 \mathrm{meq} \mathrm{g}^{-1}$, so that the sample would be more appropriately considered as hydrous mica. Five mixtures containing different proportions of both minerals were used in the study: A, pure LP; B, $90 \% \mathrm{LP}, 10 \% \mathrm{IL}$; C, $50 \% \mathrm{LP}, 50 \% \mathrm{IL}$; D, $10 \% \mathrm{LP}, 90 \% \mathrm{IL}$; and E, pure IL.

The surface charge/pH curves measured by adsorption of p.d.i. of the five mixtures were determined as described by Madrid et al. (1983) in suspensions of $0.1 \mathrm{~g}$ of solid in $20 \mathrm{ml}$ of
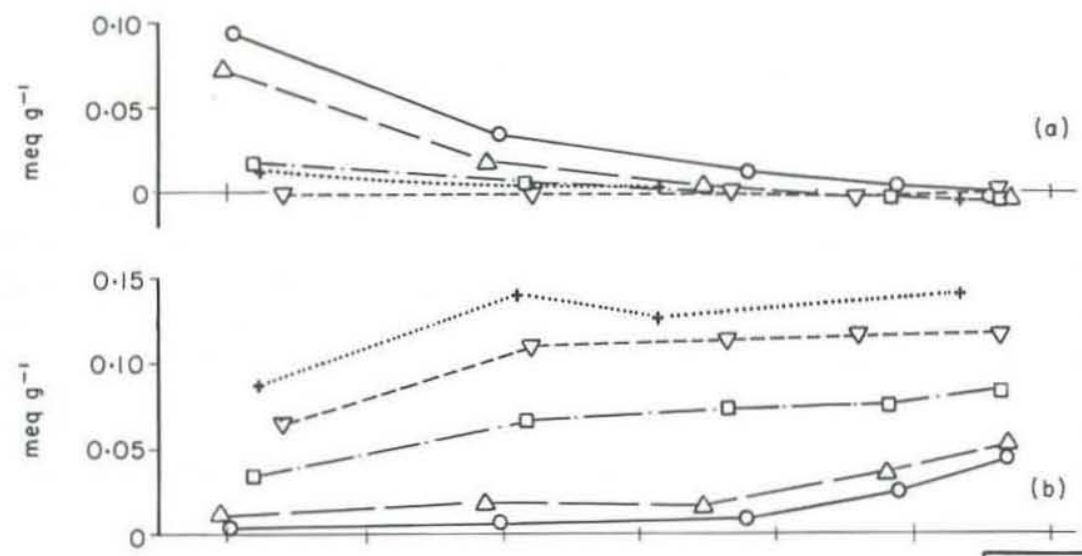

(b)

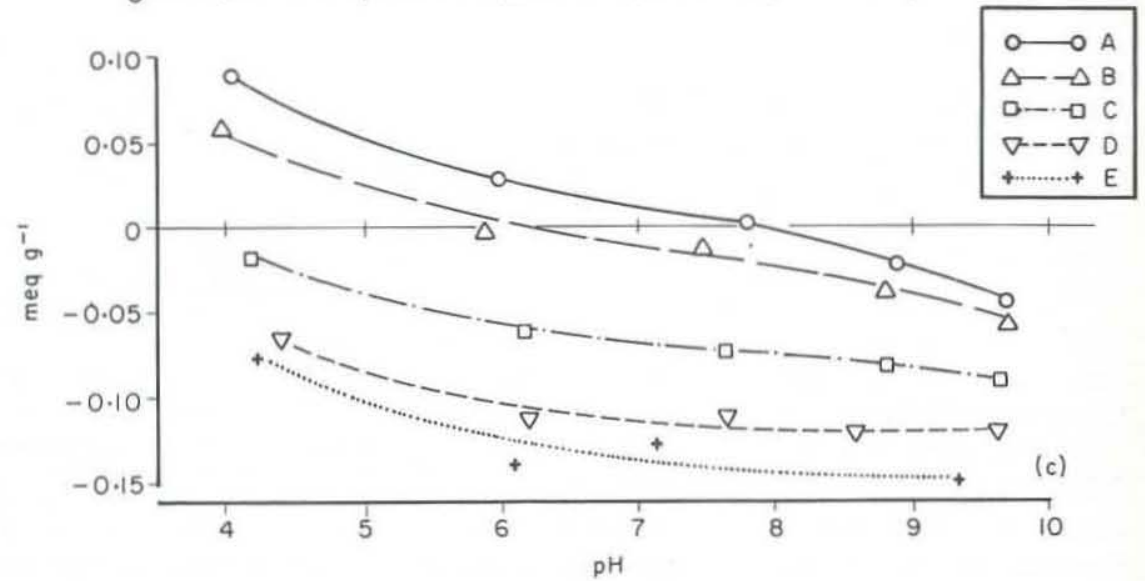

Fig. 1. Variation of (a) positive, (b) negative, and (c) net charge with $\mathrm{pH}$ in $0.01 \mathrm{M} \mathrm{NaCl}$, measured by adsorption of electrolyte ions on mixtures A-E. 


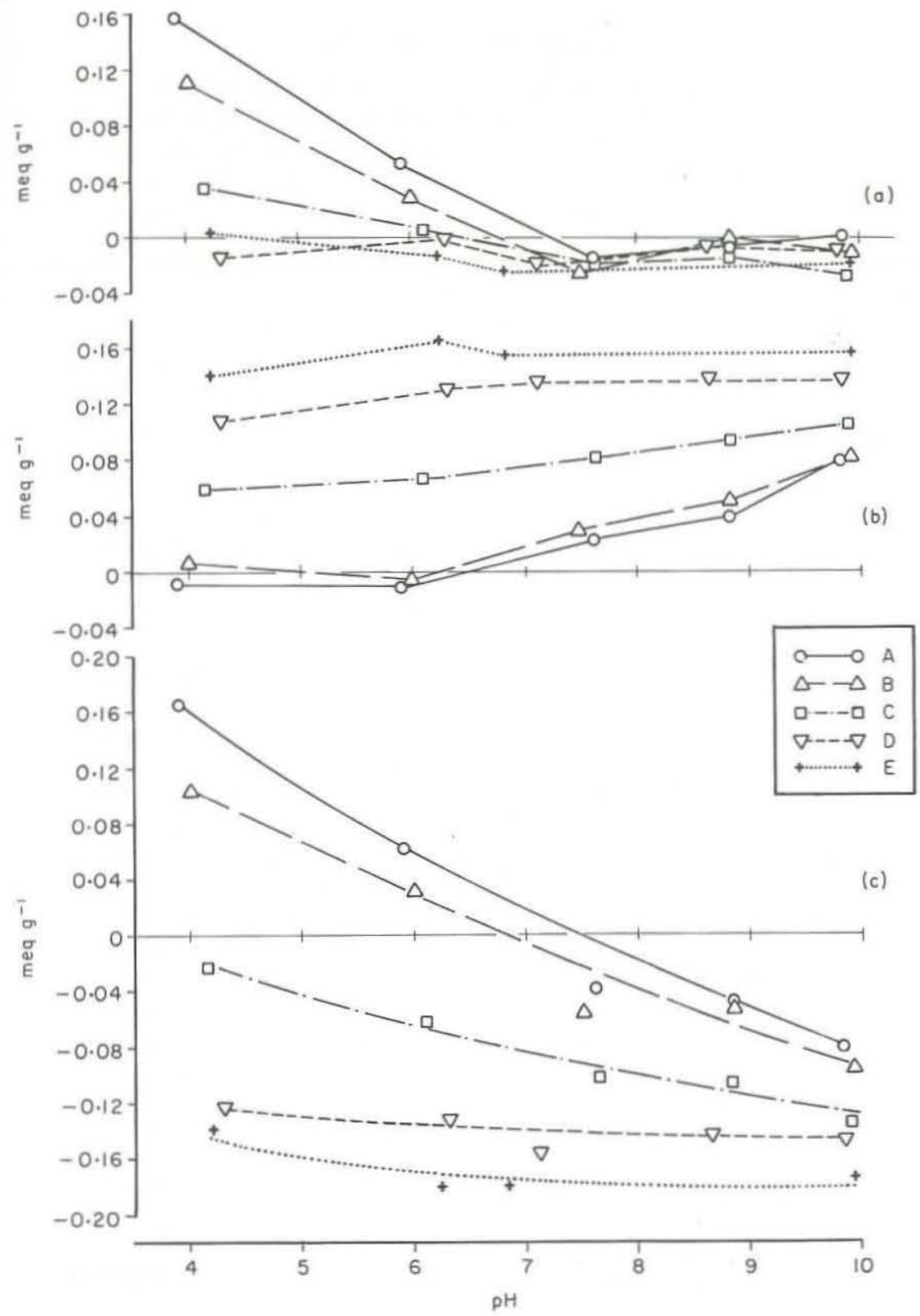

Fig. 2. Variation of (a) positive, (b) negative, and (c) net charge with $\mathrm{pH}$ in $0.1 \mathrm{M} \mathrm{NaCi}$, measured by adsorption of electrolyte ions.

$0.01,0.1$ and $1 \mathrm{M} \mathrm{NaCl}$ solutions. Adsorption of i.i. $\left(\mathrm{Na}^{+}\right.$and $\left.\mathrm{Cl}^{-}\right)$was measured by the method of Van Raij \& Peech (1972) at various pH values with 0.01 and $0.1 \mathrm{M} \mathrm{NaCl}$ as electrolyte. When the electrolyte was $1 \mathrm{M} \mathrm{NaCl}$, the entrained solution caused large errors in the determination of adsorbed ions, so that no results are given for this ionic strength. All experiments were done in duplicate.

Adsorbed $\mathrm{Na}^{+}$was determined by flame photometry, and adsorbed $\mathrm{Cl}^{-}$was measured spectrophotometrically by the mercury thiocyanate method described by Florence \& Farrar (1971). 


\section{RESULTS AND DISCUSSION}

Figs 1 and 2 show the variation of positive, negative and net charges with $\mathrm{pH}$, measured in 0.01 and $0.1 \mathrm{M} \mathrm{NaCl}$, respectively. Fig. 3 shows the $\mathrm{pH}$-dependence of the net charge measured by adsorption of p.d. ions. In Figs $3(\mathrm{a}-\mathrm{c})$ the net charge is considered to be zero at the crossover point between curves obtained at different ionic strengths, and values of ordinates are calculated relative to that point. In Fig. 3(d) the crossover point is poorly defined, so that the zero charge was taken as corresponding to the point of minimum slope. Fig. 3(e) did not give a single crossover point, so that the net charge could not be calculated, and ordinates represent absolute values of adsorption of $\mathrm{H}^{+}$or $\mathrm{OH}^{-}$after correcting for the $\mathrm{H}^{+}$or $\mathrm{OH}^{-}$consumed by the corresponding blank titrations.

As can be seen in Figs 1 and 2, the positive charge measured by $\mathrm{Cl}^{-}$adsorption seems to be due mainly to the iron oxide, since its values (Figs $1 \mathrm{a}$ and $2 \mathrm{a}$ ) decrease as the proportion of LP decreases relative to pure IL, which possesses almost no positive charge throughout the whole $\mathrm{pH}$ range studied. Negative charge measured by $\mathrm{Na}^{+}$adsorption (Figs $\mathrm{lb}$ and $2 \mathrm{~b}$ ) increases as the proportion of IL increases, and simultaneously its $\mathrm{pH}$-dependence becomes less marked, particularly for mixtures $\mathrm{D}$ and $\mathrm{E}$ above $\mathrm{pH}$. This result is in contrast with that of Greenland (1975) for kaolinite, who found a constant negative charge up to $\mathrm{pH} 6$ and then an increase between $\mathrm{pH} 6$ and 9.

Comparing curves for $\mathrm{E}$ in Figs 1 (b) and 2(b), it can be seen that the negative charge increases as the ionic strength increases. A similar conclusion was also reached when mixtures B, C and $\mathrm{D}$ were studied, after removing the contribution of LP to the total charge, vide infra (Table 2).

The fact that the charge of IL is concentration-dependent suggests that sodium ions make the IL layers expand, and some of the potassium in internal sites becomes accessible to exchange. In order to check this assumption $0.5 \mathrm{~g}$ samples of IL were extracted several times with $25 \mathrm{ml}$ portions of $\mathrm{NaCl}$ solutions at a given concentration and $\mathrm{pH}$, and potassium was determined in the extracts. The experiments were carried out at three ionic strengths $(0.01$, 0.1 and $1 \mathrm{~m}$ ) and two $\mathrm{pH}$ values (4 and 7). Results are shown in Table 1. The amounts of potassium extracted increase as the ionic strength increases, but differences between experiments in 0.01 and $0.1 \mathrm{M} \mathrm{NaCl}$ are not large enough to explain the differences between Figs I(b) and 2(b) for sample E.

In addition, the smaller amount of potassium extracted at $\mathrm{pH} 7$ compared to $\mathrm{pH} 4$ is not in line with the increase in negative charge observed in Figs $\mathrm{I}(\mathrm{b})$ and 2 (b) between $\mathrm{pH} 4$ and 7. It was therefore necessary to look for an explanation for the unexpected behaviour.

Table 1. Potassium extracted from illite $\left(\mathrm{meq}^{-1}\right)$ by $\mathrm{NaCl}$ solutions

\begin{tabular}{|c|c|c|c|c|c|c|}
\hline \multirow[b]{3}{*}{ No. extraction } & \multicolumn{6}{|c|}{$\mathrm{NaCl}$ concentration } \\
\hline & \multicolumn{2}{|c|}{$0.01 \mathrm{M}$} & \multicolumn{2}{|c|}{$0.1 \mathrm{M}$} & \multicolumn{2}{|c|}{$1 \mathrm{M}$} \\
\hline & $\mathrm{pH} 4$ & $\mathrm{pH} 7$ & $\mathrm{pH} 4$ & $\mathrm{pH} 7$ & $\mathrm{pH} 4$ & $\mathrm{pH} 7$ \\
\hline 1 & 0.024 & 0.015 & 0.032 & 0.024 & 0.033 & 0.030 \\
\hline 2 & 0.008 & 0.005 & 0.007 & 0.006 & 0.010 & 0.009 \\
\hline 3 & 0.004 & 0.003 & 0.004 & 0.003 & 0.007 & 0.006 \\
\hline 4 & 0.002 & 0.002 & 0.003 & 0.003 & 0.006 & 0.006 \\
\hline 5 & 0.002 & 0.002 & 0.002 & 0.002 & 0.005 & 0.005 \\
\hline 6 & 0.001 & 0.002 & 0.002 & 0.002 & 0.005 & 0.004 \\
\hline Total & 0.041 & 0.029 & 0.050 & 0.040 & 0.066 & 0.060 \\
\hline
\end{tabular}




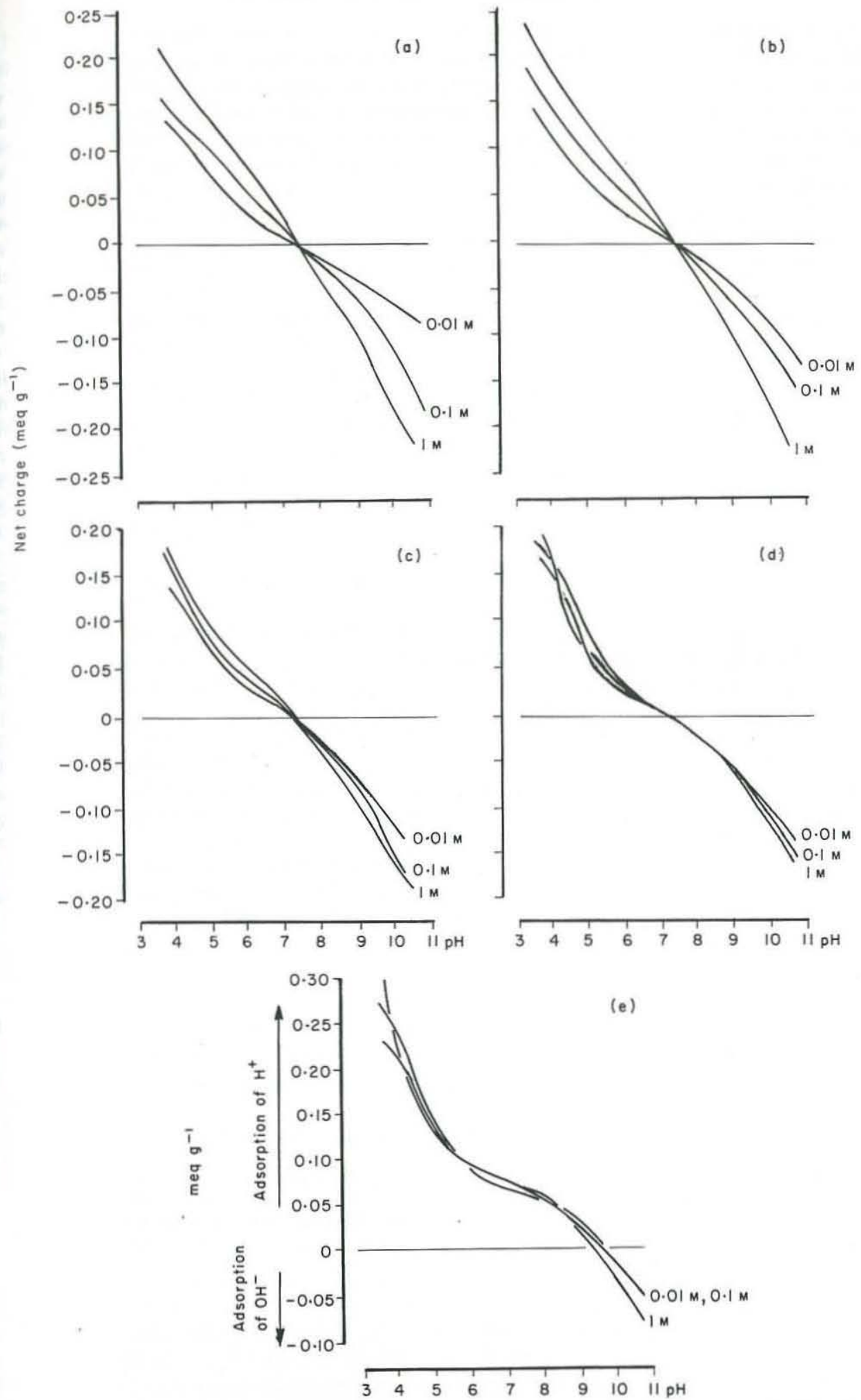

Fig. 3. Variation of net charge measured by adsorption of p.d.i. with pH: (a) mixture A; (b) mixture $\mathrm{B}$; (c) mixture C; (d) mixture D; (e) mixture E. 
Similarity between Figs $3(\mathrm{a}-\mathrm{c})$ suggests that the surfaces of mixtures $\mathrm{B}$ and $\mathrm{C}$ react with p.d.i. almost as if they were pure LP. Curves obtained at different ionic strengths gave very similar crossover points or PZSE (points of zero salt effect, according to the definitions of Parker et al., 1979) at $\mathrm{pH} 7.35,7.39$ and 7.24 for mixtures $\mathrm{A}, \mathrm{B}$ and $\mathrm{C}$ respectively, despite the fact that the PZNC (points of zero net charge) for $\mathrm{B}$ and $\mathrm{C}$ were quite far removed from these values. Figs 1 (c) and 2(c) show that the PZNC was at $\mathrm{pH}$ around 6.5 for $\mathrm{B}$ and below the studied $\mathrm{pH}$ range for $\mathrm{C}$. In other words, the presence of permanent charge does not shift the PZSE to more acid $\mathrm{pH}^{*}$ values, unlike that expected if PZSE and PZNC were coincident. As aluminium oxides have PZNC similar to iron oxides, surface coatings of hydroxy-aluminium polymers on the permanently charged IL present in mixtures B and C would explain this behaviour. Van Raij \& Peech (1972), Laverdière \& Weaver (1977) and Cabrera \& Talibudeen $(1978,1979)$ also suggested the existence of strongly held aluminium blocking exchange sites on clay mineral surfaces.

It is interesting to point out that ordinates in Figs $3(\mathrm{a}-\mathrm{c})$ reach values of charge per unit weight which are almost the same for a given $\mathrm{pH}$ and ionic strength, despite the different compositions of materials $\mathrm{A}, \mathrm{B}$ and $\mathrm{C}$. This could only happen if, on a unit weight basis, IL consumes amounts of solution $\mathrm{H}^{+}$or $\mathrm{OH}^{-}$similar to $\mathrm{LP}$, either by direct reaction with the surface or by neutralization of the aluminium hydroxy complexes already present or formed as the titration proceeds. In other words, the IL present compensates for the number of active sites associated with an equivalent weight of LP. Although no definite PZSE can be assigned to Figs 3(d-e), the total span of both groups of curves is comparable with those of Figs $3(a-c)$.

The effect of the electrolyte concentration on the separation of the p.d.i. adsorption curves seems to be less marked as the proportion of IL increases. This lack of sensitivity of the adsorption of $\mathrm{H}^{+}$and $\mathrm{OH}^{-}$by IL to changes in ionic strength can be explained if $\mathrm{H}^{+}$consumption is not only due to adsorption, but to neutralization of the hydroxy polymers coating the IL surfaces. This latter reaction could be less sensitive to changes in salt concentration. The increase in negative charge between $\mathrm{pH} 4$ and 6 (Figs $1 \mathrm{~b}$ and $2 \mathrm{~b}$ ) and between systems containing $0.01 \mathrm{M}$ and $0.1 \mathrm{M} \mathrm{NaCl}$ cannot be related to dissolution of hydroxy-aluminium coatings, as treatments of IL with $\mathrm{NaCl}$ solutions extracted very small amounts of aluminium which were within the experimental error of the colorimetric method and much lower than those shown in Table 1 for potassium. Nevertheless, an alternative explanation could be that suggested by Sawhey et al. (1970), who showed that coatings of hydroxy-aluminium complexes could release exchange sites in soils of the temperate regions by precipitation of well-formed hydroxides, and this increase in CEC would be irreversible, unlike the increase in CEC due to the presence of weak organic acids or to adsorption of $\mathrm{H}^{+}$or $\mathrm{OH}^{-}$ions on iron or aluminium oxides, which would be reversible.

Table 2. Permanent charge of the illite $\left(\mathrm{meq}^{-1}\right)$ present in mixtures B, C and D

\begin{tabular}{ccccc}
\hline $\begin{array}{c}\mathrm{NaCl} \\
\text { concentration }\end{array}$ & B & C & D & Mean $\pm \mathrm{SD}$ \\
\hline $0.01 \mathrm{M}$ & 0.13 & 0.14 & 0.12 & $0.13 \pm 0.01$ \\
$0.10 \mathrm{M}$ & 0.17 & 0.17 & 0.15 & $0.16 \pm 0.01$ \\
\hline
\end{tabular}

The net electric charge measured by adsorption of i.i. can be utilized to make an estimation of the 'permanent' charge of the IL present in mixtures B, C and D. At the PZSE, obtained from Fig. 3, the variable charge must be zero, so that the net charge in Figs 1(c) and 2(c) at the same $\mathrm{pH}$ as the PZSE should only include the permanent charge of IL. Taking into account the contents of IL in each mixture, the values in Table 2 were obtained. 
It can be seen that all results are very similar at a given ionic strength, so that the difference between the mean values for 0.01 and $0.1 \mathrm{M} \mathrm{NaCl}$ is highly significant.

It should be noted that the results suggest that many empirical methods of CEC determination based on equilibration of soils or clay minerals with concentrated solutions of a given cation $\left(\mathrm{NH}_{4}^{+}, \mathrm{Ba}^{++}\right.$, etc.) are likely to over estimate the CEC. Most reactions in which the CEC is a relevant factor take place in dilute systems, and even model substances like the clay mineral used by the authors may have variable charge components which create a salt concentration dependent CEC.

\section{MODELLING CHARGE PROPERTIES OF MIXED SYSTEMS}

A rigorous mathematical treatment of materials with both permanent and $\mathrm{pH}$-dependent charge is difficult. Uehara \& Gillman (1980) described a simple model for this type of material based on Nernst and Gouy-Chapman equations, but its applicability is seriously limited by two assumptions which are only justified when the proportion of permanent charge is very low. These are (a) when Uehara \& Gillman (1980) suppose that the variable charge is given by the Gouy-Chapman equation for the diffuse layer they forget that the diffuse charge must compensate for both permanent and variable charges, otherwise the principle of electrical neutrality would not hold; and (b) when these authors identify the surface electric potential with that given by Nernst equation (applied to the p.d.i.) they neglect the influence that the permanent charge would have on such surface potential.

The Stern model in the form used by Bowden et al. (1977) can be adapted to mixed materials such as those used here, but some modifications should be considered:

(a) The adsorption of p.d.i. is supposed to occur on two kinds of sites, on the oxide and on the clay mineral. The Stern-type equation given by Bowden et al. (1977) should therefore contain the sum of two similar terms, one for the adsorption on each surface. To minimize the mathematical complexity of the model, the surface potential can be supposed to have a unique 'average' value, even though it is likely that there exist local variations of the surface potential according to the type of surface.

(b) The equation expressing the electrical neutrality of the system should contain a constant term representing the permanent charge of the clay mineral.

(c) Due to the large number of parameters to be estimated by iteration, some simplifications can be introduced, e.g. binding constants of p.d.i. $\mathrm{H}^{+}$and $\mathrm{OH}^{-}$for the iron oxide surfaces can be supposed to have fixed values, similar to those given elsewhere (Madrid et al., 1983; Bowden et al., 1977; Barrow et al., 1980).

\section{ACKNOWLEDGEMENTS}

The authors wish to thank Mrs M. F. Osta for her valuable help in chloride and sodium determinations, and Dr J. L. Pérez for providing us with the illite samples and for his valuable advice.

\section{REFERENCES}

Barrow, N.J., Bowden, J.W., Posner, A.M. \& QUiRK, J.P. 1980. An objective method for fitting models of ion adsorption on variable charge surfaces. Australian Journal of Soil Research $18,37-47$.

Bowden, J.W., Posner, A.M. \& Quirk, J.P. 1977. Ionic adsorption on variable charge mineral surfaces. Theoretical charge development and titration curves. Australian Journal of Soil Research 15, 121-136.

Cabrera, F. \& TalibudeEn, O. 1978. The release of aluminium from aluminosilicate minerals. I. Kinetics. Clays and Clay Minerals 26, 434-440.
Cabrera, F. \& Talibudeen, O. 1979. The release of aluminium from aluminosilicate minerals. II. Acid-base potentiometric titrations. Clays and Clay Minerals 27, 113-118.

Florence, T.M. \& Farrar, Y.J. 1971. Spectrophotometric determination of chloride at the parts-per-billion level by the mercury (II) thiocynate method. Analytica Chimica Acta 54, 373-377.

GREenland, D.J. 1975. Charge characteristics of some kaolinite-iron hydroxide complexes. Clay Minerals 10, 407-416.

LAVERDiĖre, M.R. \& Weaver, R.M. 1977. Charge 
characteristics of spodic horizons. Soil Science Society of America Journal 41, 505-510.

Madrid, L., Diaz, E., Cabrera, F. \& Arambarri, P. DE 1983. Use of a three-plane model to describe charge properties of some iron oxides and soil clays. Journal of Soil Science 34, 57-67.

Parker, J.C., Zelazny, L.W., Sampath, S. \& HarRIS, W.G. 1979. Critical evaluation of the extension of zero point of charge (ZPC) theory to soil systems. Soil Science Society of America Journal 43, 668-674.
SAWhNeY, B.L., Frink, C.R. \& HiLl, D.E. 1970 Components of $\mathrm{pH}$-dependent cation exchange capacity. Soil Science 109, 272-278.

Uehara, G. \& Gillman, G.P. 1980. Charge characteristics of soils with variable and perma. nent charge minerals. I. Theory. Soil Science Society of America Journal 44, 250-252.

VAN RAIJ, B. \& PEECH, M. 1972. Electrochemical properties of some Oxisols and Alfisols of the tropics. Soil Science Society of America Proceedings 36, 587-593.

(Received 18 August 1983) 